\title{
META-ANALYSIS: THE EFFECT OF FAMILY HISTORY OF BREAST CANCER ON EARLY DETECTION BEHAVIOR USING MAMMOGRAPHY
}

\author{
Amanda Via Maulinda'), Bhisma Murti'1), Rita Benya Adriani²) \\ 1)Masters Program in Public Health, Universitas Sebelas Maret \\ ${ }^{2)}$ Health Polytechnics, Ministry of Health Surakarta
}

\begin{abstract}
Background: Several well-established risk factors have been shown to be associated with screening practices among women, including socioeconomic status, demographic factors, health behavior, as well as cultural and psychosocial factors. However, less studies has examined the association between family history of breast cancer and screening practices in women. A variety of screening tests are used to detect breast cancer e.g., mammography, ultrasound, MRI, clinical breast examination, and breastself examination. This study aimed to investigate the effect of family history of breast cancer on early detection behavior using mammography.

Subjects and Method: This was a systematic review and meta-analysis. This study was conducted in multiple databases including PubMed, Science Direct, Google Scholar, Springerlink, and complemented by cross-referencing to identify crosssectional studies published from 2009 to 2018. The following search terms were used: Mammography AND "family history breast cancer" AND "cross sectional". The inclusion criteria were English full text and randomized controlled trial. The articles were filtered using PICO model, including: (1) Population= women of reproductive age, (2) intervention = family history of breast cancer, (3) comparison= no family history of breast cancer, and (4) outcome= early detection behavior using mammography. The inclusion criteria were full-text and reported adjusted Odds Ratio (aOR). The systematic review was carried out according to the PRISMA guidelines. Data analysis were performed using RevMan 5.3.

Results: 6 studies from Taiwan, Japan, United States, Mexico, Qatar, Turkish, and Hong Kong were involved for meta-analysis. This study showed that family history of breast cancer elevated early breast cancer detection behavior using mammography $(\mathrm{aOR}=1.59 ; 95 \% \mathrm{CI}=1.40$ to $1.80 ; \mathrm{p}<0.001)$.
\end{abstract}

Conclusion: Family history of breast cancer elevates early breast cancer detection behavior using mammography.

Keywords: family history, breast cancer, breast cancer detection, behavior, mammography

\section{Correspondence:}

Amanda Via Maulinda. Masters Program in Public Health, Universitas Sebelas Maret. Jl. Ir. Sutami 36A, Surakarta 57126, Central Java. Email: viaamanda80@student.uns.ac.id. Mobile: 085736228812. 